\title{
Invasion in a Community Context: Genetic Variation in the Strength of Direct and Indirect Effects
}

\section{Carmen Hoffbeck}

California State University Northridge https://orcid.org/0000-0002-0685-8505

\section{Nicole Cammisa}

University of California Los Angeles Institute of the Environment and Sustainability

Casey P terHorst ( $\nabla$ casey.terhorst@csun.edu )

California State University Northridge https://orcid.org/0000-0001-7261-2178

\section{Research Article}

Keywords: Drought, Evolution, Indirect Effects, Invasive Species, Mutualism

Posted Date: October 29th, 2021

DOI: https://doi.org/10.21203/rs.3.rs-897913/v1

License: (1) This work is licensed under a Creative Commons Attribution 4.0 International License. Read Full License 
5

$9 \quad{ }^{1}$ Biology Department, California State University, Northridge

$10{ }^{2}$ Present address: Institute of the Environment and Sustainability, University of California,

11 Los Angeles

12

$13 *$ Corresponding author: casey.terhorst@csun.edu

14

Author Contributions: NC and CPt conceived and designed the experiments. NC performed the experiments. $\mathrm{NC}$ and $\mathrm{CH}$ analyzed the data. $\mathrm{CH}$ performed the meta-analysis. $\mathrm{CH}, \mathrm{CPt}$, and NC wrote the manuscript. 


\section{Abstract}

Predicting invasion success requires understanding how abiotic and biotic factors in

17 the local environment interact with the particular traits of potential invaders. Relative to

18 studies of direct antagonistic effects, fewer studies have examined how positive species

19 interactions, such as facilitation or mutualism, or indirect interactions in multispecies

20 communities, can affect invasion success. We examined the effects of drought and

21 mutualisms with rhizobia bacteria on the performance of a widely invasive legume,

22 Medicago polymorpha. In a greenhouse experiment, we found that watering regime affected

23 plant performance, but non-linear patterns in response to decreasing water were dependent on

24 the specific plant genotype. In a second experiment, we found that the effects of drought on

25 plant performance were dependent on the presence of rhizobia, particularly for genotypes

26 collected from the invasive range. This suggests that indirect ecological effects may have

27 important consequences for invasion success. We contextualize the strength of these direct

28 and indirect effects by comparing this study to effect sizes in other studies of the same

29 species. In this species, predicting invasion into a natural community context will require

30 understanding multiple direct and indirect effects in the local environment, as well as their

31 effects on the specific genetic composition of the invading population.

32

33 Key words: Drought, Evolution, Indirect Effects, Invasive Species, Mutualism 
Introduction

Invasive species are an ongoing and increasing threat to ecosystems and economies around the world (Moser et al., 2009; Paini et al., 2016). Predicting and preventing invasion success requires understanding the abiotic and biotic factors in the local environment that influence invader performance and the invader traits that allow individuals to overcome barriers to invasion. Habitats can exhibit abiotic resistance to plant invasion through drought and disturbance (Bever et al., 1997; Duchicela et al., 2012; Bayliss et al., 2017), nutrient availability (Davis et al., 2000; McGlone et al., 2011; Zefferman et al., 2015), or other factors that decrease invader performance. Further, communities can confer biotic resistance to invasion through antagonistic species interactions between native and non-native species, such as competition (Bever, Platt, and Morton 2012; Pages and Michalet 2003), herbivory (Hillebrand et al., 2008; Bayliss et al., 2017), or negative effects of the soil bacterial community on plant performance (Bever, 2015; Revillini et al., 2016; Hansen et al., 2020). Fewer studies have examined how positive species interactions, such as facilitation or mutualism, or indirect interactions in multispecies communities, can affect invasion success (Aslan, 2019; Cavieres, 2021).

The consequences of direct abiotic effects on native plant communities and nonnative plant invaders, particularly nutrient level, drought, and disturbance, have been wellstudied. The availability of nutrients such as nitrogen and phosphorous can be altered by both native and invasive plant species, which can affect invasion success or create deleterious effects on native plant communities (Huenneke et al., 1990; Kulmatiski et al., 2006; Rosenblatt, 2018). Prolonged drought influences reproduction and growth of many plant species, and many plants will not set seed in drought conditions (Thalmann \& Santelia, 2017;

57 Rosenblatt, 2018). However, when invasive species are more tolerant of drought than their native counterparts, they may have a competitive advantage that increases invasion success 
59 (Everard et al., 2010). Fire or other natural disturbances can physically damage plants, affect

60

61

62

63

64

65

66

67

68

69

70

71

72 seed banks, and create available space in plant communities that differentially affects species adapted to such disturbances (Kinnaird \& O’Brien, 1998; Lentile et al., 2007; Knutson et al., 2014). Other anthropogenic effects, such as agriculture, land use changes, or climate change can also create disturbances in natural communities that can affect invasion success (Kuhman et al., 2013; González-Moreno et al., 2013; Csecserits et al., 2016). Such disturbances often affect soil nutrient levels, and different plant responses to nutrient availability can alter the likelihood of plant invasion success (Huenneke et al., 1990; Kulmatiski et al., 2006).

Negative species interactions can increase biotic resistance to invasion (Maron \& Vilà, 2001; Levine et al., 2004; Mitchell et al., 2006). Antagonistic effects from natural enemies, such as herbivores, can physically damage leaves and roots, cause reallocation of resources away from reproduction, or stress plants such that invader performance is reduced (Edwards et al., 2000; Rand, 2003; Gianoli et al., 2009). Competition from other plants can also decrease invader performance by limiting access to light and nutrients (Weber \& Kolb, 2013; Shabbir et al., 2020). Positive species interactions may also play a role in determining biotic resistance to invasion. Plant mutualists, such as pollinators, fungal mycorrhizae, or rhizobial bacteria may be required for reproduction or access to limiting resources in lownutrient habitats (Marschner et al., 2001; Berg et al., 2014; Fang et al., 2019) and thus their absence may be considered a form of biotic resistance. Some plant species are only able to invade after the introduction of their mutualist partners (Halliday \& Somasegaran, 1983; Richardson et al., 2000; Dickie et al., 2017).

Although many studies have identified abiotic and biotic factors that contribute to resistance to invasion, fewer studies have considered the complexities that arise when we account for multiple factors. Potential invaders face a complex web of novel abiotic and biotic interactions when they attempt to invade a community and these ecological interactions 
rarely occur in isolation. Predicting invasion success in natural habitats requires

understanding the consequences of multiple direct effects, as well as indirect ecological interactions. Biotic interactions may ameliorate or intensify the effects of abiotic stressors,

87 resulting in indirect ecological interactions that affect plant performance (Gianoli et al., 2009;

88 Rosenblatt, 2018; Szczepaniec \& Finke, 2019). For example, the presence of mycorrhizal symbionts can increase performance in plants exposed to water stress (Jayne \& Quigley, 2014). Increased abundances of invasive plants can increase local herbivore abundances, which can indirectly affect native plant performance (Rand, 2003). Allelopathy by either native or invasive plants may affect invader performance by chemically altering soil composition or changing the composition of the microbial community (Cipollini \& Cipollini, 2016; Algandaby \& El-Darier, 2018). Such indirect ecological effects have proven to be important in a variety of systems, often rivaling the strength of direct interactions (Strauss, 1991; Wootton, 1994; Dill et al., 2003).

If a single direct ecological interaction is the primary driver of invasion success in a community, then we may already have a firm grasp on successful management practices for many non-native species. However, if indirect ecological interactions are similarly important, then we cannot understand invasion resistance in a community context without accounting for direct and indirect effects. Invasive species management approaches that combine multiple

102 factors, such as competition and nutrient levels, can have a greater affect than managing 103 either factor in isolation (Edwards et al., 2000).

Study Species

Medicago polymorpha is a legume native to the Mediterranean that has invaded every continent in the world, except Antarctica (Bullitta et al., 1994). It is frequently used in agriculture as a cover crop, but can escape agricultural settings to surrounding environments and beyond (Bullitta et al., 1994; Porter \& Simms, 2014). Once established in natural 
environments, M. polymorpha can compete with native plants, and is difficult to eradicate because the burrs are easily dispersed by animals and can remain in the soil for years. Work on invasive M. polymorpha populations has focused on direct ecological effects like herbivory (Jack \& Friesen, 2019), mutualism with rhizobia (Porter \& Simms, 2014), and competition (Algandaby \& El-Darier, 2018), alongside others. Less work has examined indirect effects involving M. polymorpha. The presence of M. polymorpha increased herbivory on native Acmispon (formerly Lotus) wrangelianus (Lau \& Strauss, 2005), presumably because insect herbivores cue in on or find the invasive species more easily, but then switch to consume the native species as well. Disturbance and insect herbivory interact, in that disturbance increased M. polymorpha flowering, but only in the absence of insect herbivores (Bayliss et al., 2017). In another study, rhizobia were found to increase $M$. polymorpha tolerance of interspecific competition and effects on competitor biomass (terHorst et al., 2018).

The consequences of ecological interactions with M. polymorpha may largely depend on intraspecific variation within this species. For example, strains of M. polymorpha originating from arid environments have higher drought tolerance than strains from more humid climates (Yousfi et al., 2015; Badri et al., 2016). The extent to which rhizobia affect competition with $M$. polymorpha depended on the plant genotype and the location from which they were collected (terHorst et al., 2018). Indirect effects of rhizobia on competition were relatively small in plants collected from the native range, but plants collected from the broad invasive range of this species showed highly variable indirect effects, ranging from rhizobia greatly decreasing the effects of competition in some genotypes, to rhizobia increasing the negative effects of competition in other genotypes (terHorst et al., 2018). Presumably, genotypes collected in the native range reflect adaptive traits in a relatively narrow range of environmental conditions, whereas genotypes from the invasive range reflect 
traits adaptive in the invasive range, which encompasses a broad array of different environmental conditions. This suggests that invasion success depends not only on the combination of direct and indirect effects at a potential invasion site, but also on the particular genetic composition of the introduced population.

In this paper, we seek a more comprehensive approach to understanding plant invasions that accounts for the community context in which invasions occur and intraspecific variation in responses to potential barriers to invasion. We ask whether such a framework provides more insight into how plant invasions occur, or whether our existing understanding of individual direct effects is sufficient. We use Medicago polymorpha as a model species to understand barriers to invasion more broadly and to better understand the role of community context in understanding how species expand their ranges, taking both direct and indirect effects into account. Here we present the results of two experiments that examined direct and indirect effects of drought and mutualisms with rhizobia on M. polymorpha fitness. Then we contextualize these results by comparing the magnitude of direct and indirect effects in these experiments to previously published direct and indirect effect sizes of M. polymorpha ecological interactions.

\section{Methods}

\section{Direct effects of drought}

We used a greenhouse study to test the effects of drought on different genotypes of $M$. polymorpha. We used 5 haphazardly selected M. polymorpha ascensions from the U.S.

National Plant Germplasm System. Because this species reproduces almost entirely through selfing, resulting in homozygous clones, we refer to these ascensions as genotypes. These genotypes were collected from different parts of the species range, with three from the native range (292427 from Israel, 469263 from Egypt, and 543039 from Spain) and two from the 
invasive range (478530 from Peru and w65527 from Australia). Genotypes were categorized (https://www.cabi.org/ISC). All genotypes were grown in a common garden greenhouse environment for one generation prior to the experiment to ensure that any observed differences among genotypes were due to genetic differences, rather than maternal or epigenetic effects. Seeds collected from this common garden generation were used in the experiment.

M. polymorpha seeds were scarified and planted in $164 \mathrm{~mL}$ conetainers (Stuewe and

167 Sons, Tangent, OR, USA) containing low-nitrogen LP5 Grower Mix soil (SunGro, Agawam,

168 MA, USA), composed of 90\% topsoil, 9\% sand (DecoRock All Purpose), and 1\% perlite.

169 Plants were grown in the California State University, Northridge greenhouse with conetainers

170 haphazardly distributed among racks, with racks rotated weekly to reduce any microclimate

171 effects. We planted three seeds of each of the five genotypes in replicate conetainers and after

172 two weeks, thinned the seedlings to one per pot. We transplanted removed seedlings to new

173 conetainers when possible.

174 Plants were watered daily for 28 days and watering treatments were imposed

175 thereafter. We watered plants in all treatments approximately every two days, with some

176 adjustments based on the local temperature. On the few occasions where the outside

177 temperature exceeded $29^{\circ} \mathrm{C}$, plants were watered daily. All plants were watered with the

178 same frequency, but with different volumes: Level $1=100 \mathrm{~mL}$, Level $2=50 \mathrm{~mL}$, Level $3=$

$17925 \mathrm{~mL}$, Level $4=12.5 \mathrm{~mL}$ per conetainer. These volumes were based on preliminary data

180 showing that plants experienced signs of water stress after two days in the smallest volume

181 treatment, but did not die. The ecological relevance of these watering regimes differs

182 depending on the potential invasion site and the origin of each genotype. 

seedlings led to 14-26 replicates per treatment combination $(\mathrm{N}=411)$. In June 2016, 29 days after the watering levels were imposed, we harvested the plants and separated above- and belowground biomass of each plant and dried these at $50^{\circ} \mathrm{C}$ for three days, and then weighed dry biomass using an analytical balance. We used total plant biomass (aboveground + belowground biomass) as a measure of plant size and performance and the ratio of above:belowground biomass to determine if biomass allocation to shoots and roots differed across the four watering levels or plant genotype.

Direct and indirect effects of drought and rhizobia

We conducted a similar study in 2015 with 43 haphazardly chosen M. polymorpha genotypes (18 collected from the native range and 25 collected from the invasive range; Table S1). We manipulated watering level at only two treatment levels in this experiment and also manipulated the availability of rhizobia in the soil. Seedlings were established in conetainers as above, with three replicates per genotype, and were grown in the outdoor botanical garden at California State University, Northridge. This experiment included 516 plants (43 genotypes x 2 watering treatments $\mathrm{x} 2$ rhizobia treatments $\mathrm{x} 3$ replicates). We randomly distributed replicates among two rhizobia treatments. In the enhanced rhizobia treatment, we supplemented the soil with rhizobia collected from the nodules of $M$. polymorpha plants in the botanic garden at California State University, Northridge in December 2014. M. polymorpha associates almost exclusively with the bacterium Ensifer medicae in laboratory and field conditions (Ballard et al., 2004; Porter et al., 2011). We collected nodules from plant roots and surface sterilized them with sequential rinses in $10 \%$

207 bleach, 95\% ethanol, and sterile deionized water (adapted from Somasegaran \& Hoben, 
1985). We crushed the surface-sterilized nodules in sterile deionized water and plated the solution on tryptone yeast (TY) agar plates. We incubated plates at $25^{\circ} \mathrm{C}$ and found only colonies with the same morphology as E. medicae (Somasegaran \& Hoben, 1985). We used multiple colonies to inoculate a heat-sterilized TY nutrient broth. We simultaneously started a sterilized broth of TY media without the rhizobia inoculant. Both media were cultured at $25^{\circ} \mathrm{C}$ for 24 hours before use. We added $1 \mathrm{~mL}$ of media (either rhizobia-inoculated or the sterile control) around the base of 2-week-old M. polymorpha seedlings (terHorst et al., 2018). We assumed rhizobia to be absent or in low abundance in the commercial soil prior to inoculation and did not control for colonization of rhizobia from the environment during the experiment. We did not quantify rhizobia abundance in the soil, but assume that the addition of rhizobia greatly increased their abundance. We refer to these as Enhanced or Background rhizobia treatments.

We randomly distributed replicates among two watering treatments that we imposed six days after rhizobia inoculation. All plants received $100 \mathrm{~mL}$ of water each time they were watered. Plants in the high watering treatment were watered approximately four times more often than those in the low watering treatment. Plants in the high water treatment were watered approximately every two days, but occasionally daily when the temperature was particularly high; watering was delayed a day following rare precipitation events. In the low watering treatment, we only watered plants following signs of water stress, such as leaf folding or mild wilting. In April 2015, 28 days after the watering treatments were imposed, we harvested the plants. Plant biomass was divided into above- and belowground components and weighed as dry mass, as above.

\section{Statistical analysis}

For the greenhouse experiment, we fit generalized linear mixed models using $\mathrm{R}$ to examine the fixed effects of watering level, plant range (native or invasive), and their 
interaction on total biomass and above:belowground biomass ratio. We included genotypes nested within range, and the interaction between watering level and genotype as random effects in the models. We found the best-fit model and error distribution for each dependent variable (gamma distribution in each case) by comparing Akaike Information Criteria (AIC) values. Interaction terms and random effects were dropped from the model if their inclusion did not result in a lower AIC value. Genotype was retained in all models to avoid pseudoreplication in the experimental design. We performed likelihood ratio tests to determine the significance of random factors. We conducted similar analyses for the botanical garden experiment, but included rhizobia treatment as a fixed effect and the genotype*rhizobia interaction as a random effect.

\section{Comparing direct and indirect effect sizes to previous studies}

Web of Science, and JSTOR search for keywords "Medicago polymorpha", "M. polymorpha", and "Medicago". We selected papers with experimental manipulations of ecological interactions with $M$. polymorpha, and if sample size and variance could be determined from the paper. Standardized effect size for direct effects and confidence intervals were calculated using Cohen's d (Ziegel et al., 1995). control. For example, the direct effect of rhizobia in the second experiment was calculated as the difference in a variable $(\mathrm{X})$ between the Enhanced rhizobia treatment $\left(\mathrm{X}_{2}\right)$ and the

253 Background rhizobia treatment $\left(\mathrm{X}_{1}\right)$, standardized by the pooled standard deviation and multiplied by a corrector for sample size (J):

255

$$
\frac{X_{2}-X_{1}}{\sqrt{\frac{\left(n_{1}-1\right) s_{1}^{2}+\left(n_{2}-1\right) s_{2}^{2}}{n_{1}+n_{2}-2}}} * J
$$



treatments $\left(\mathrm{X}_{2}\right.$ and $\left.\mathrm{X}_{3}\right)$ as in terHorst et al. (2015).

$$
\mathrm{X}_{\text {additive }}=\mathrm{X}_{1}+\left(\mathrm{X}_{2}-\mathrm{X}_{1}\right)+\left(\mathrm{X}_{3}-\mathrm{X}_{1}\right)=\mathrm{X}_{2}+\mathrm{X}_{3}-\mathrm{X}_{1}
$$

We also calculated standardized indirect effect sizes using an equivalent of Cohen's d.

We calculated the difference between the observed variable in the presence of both interactions $\left(\mathrm{X}_{4}\right)$ and the additive effect of both interactions based on direct effects (terHorst et al. 2015).

$$
\mathrm{X}_{\text {indirect }}=\mathrm{X}_{4}-\mathrm{X}_{\text {additive }}
$$

We standardized this indirect, or non-additive, effect by the pooled standard deviation, resulting in this standardized indirect effect comparable to direct effects:

$$
\frac{X_{4}-X_{2}-X_{3}+X_{1}}{\sqrt{\frac{\left(n_{1}-1\right) s_{1}^{2}+\left(\left(n_{2}-1\right) s_{2}^{2}+\left(n_{3}-1\right) s_{3}^{2}+\left(n_{4}-1\right) s_{4}^{2}\right.}{n_{1}+n_{2}+n_{3}+n_{4}-4}}}
$$

Similarly, we calculated direct and indirect effect sizes from previous studies on $M$. polymorpha in response to various ecological interactions. We took the absolute value of each effect size and grouped these as direct effects of drought, disturbance, herbivory, nutrient level, competition, and mutualism, as well as indirect effects (Table S2). We further distinguished the studies by their use of native or invasive range genotypes of $M$. polymorpha, categorized by origin in the Mediterranean or outside of that region, using the reported genotypes, strains, or collection sites identified in each study. Because there were relatively few studies within each category, we did not conduct a formal statistical analysis.

\section{Results}

In the greenhouse experiment, $95 \%$ of replicate plants survived the experiment, resulting in an average sample size of $20($ range $=11-26)$ across treatment*genotype combinations. The size of $M$. polymorpha plants was determined by the interaction between 
genotype and watering treatment $\left(\mathrm{X}^{2}=26.1, \mathrm{P}<0.001\right)$. Genotypes exhibited variation in both

281 the direction and magnitude of their responses (Fig. 1A). The genotype from Australia

282 (w65527), on average, grew to the largest size, but was the most affected by decreasing water

283 to the lowest level. In contrast, the genotype from Spain (543039) had the smallest plants, but

284 was relatively unaffected by different watering levels. The genotype from Israel (292427)

285 grew largest with intermediate watering, but the genotype from Egypt (469263) grew largest

286 at the highest and lowest watering levels.

Plant genotypes allocated above- and belowground biomass differently in

response to the watering treatments. On average, genotypes from the native range allocated

more resources toward aboveground growth relative to genotypes from the invasive range

(Range: $\mathrm{F}_{1,4}=22.5, \mathrm{P}=0.001$ ), although there was also significant variation among

genotypes within range $\left(\mathrm{X}^{2}=22.6, \mathrm{P}<0.001\right.$, Fig. 1B). Each genotype also displayed different growth allocation responses to different watering levels. Two genotypes had the highest

allocation toward belowground biomass at the lowest watering level, but the remaining genotypes had variable responses (Fig 1B).

In the botanical garden experiment, survival was similar to the greenhouse experiment $(95 \%)$. The effect of the watering treatment was dependent on the rhizobia treatment and the range from which genotypes were collected $\left(\mathrm{F}_{1,396}=4.68, \mathrm{P}=0.031\right)$. Invasive genotypes grown in the high water and enhanced rhizobia treatment produced the most biomass (Fig. enhanced rhizobia (Fig. 2A). However, native genotypes grew larger with enhanced rhizobia in the low water treatment (Fig. 2A). Conversely, invasive genotypes grown in the low water treatment were actually smaller in the enhanced rhizobia treatment, but benefitted from rhizobia in the high water treatment. Beyond the effects of collection range, different genotypes responded differently to watering treatments $\left(X^{2}=11.6, \mathrm{df}=1, \mathrm{P}<0.001\right)$. In the 
background rhizobia treatment, most genotypes responded negatively to the low water

306

307

308

309

310

311

312

313

314

315

316

317

319

320

321

322

323

324

325

326

327

328

329

treatment, albeit to different extents, but nine genotypes had positive average responses to the low water treatment (Fig. 3A). However, in the enhanced rhizobia treatment, the rank-order of effects of watering on M. polymorpha biomass was quite different (Fig. 3B), reflecting the fact that different genotypes responded to the watering and rhizobia treatments differently. Biomass allocation to above- and belowground biomass depended on the interaction between watering treatment and plant genotype $\left(\mathrm{X}^{2}=7.37, \mathrm{df}=1, \mathrm{P}=0.007\right)$. The effects of genotype on changes in biomass allocation with different watering treatments was not significantly related to collection range of those genotypes (Range*Water: $\mathrm{F}_{1,41}=0.43, \mathrm{P}=$ 0.516). The range*water*rhizobia interaction also had no significant effect on the above:belowground biomass ratio $\left(\mathrm{F}_{1,372}=0.28, \mathrm{P}=0.595\right)$. On average though, genotypes collected from the native range allocated more energy toward aboveground biomass than invasive genotypes $\left(\mathrm{F}_{1,41}=5.98, \mathrm{P}=0.019\right.$, Fig. $\left.2 \mathrm{~B}\right)$.

In our second experiment, drought had similarly large direct effects on the size of plants from the native and invasive range (Cohen's d: native $=0.43$, invasive $=0.45$ ).

Rhizobia had much smaller direct effects on plant size, but were twice as high on plants from the native range compared to invasive range plants (native $=0.17$, invasive $=0.08$ ). Indirect effects between drought and rhizobia were nearly as strong as direct effects for plants from the invasive range (0.34), but much smaller for plants from the native range (0.04). To contexualize these effects, we also compared these results to other studies of ecological interactions with $M$. polymorpha. Our direct and indirect effects were relatively weak compared to previous studies on this species (Fig. 4). In decreasing order of effect size, mutualism, nutrients, competition, drought, disturbance, and herbivory had greater effects on M. polymorpha abundance than those observed in this study. However, consistent with previous studies, effect strengths were dependent on whether genotypes originated from the 
native or invasive range. Native range genotypes were affected more by interactions with mutualists, whereas invasive range genotypes were affected more by nutrients, drought, and herbivory. In past studies, indirect effects were smaller in magnitude than direct effects,

333 inconsistent with the results observed in this study.

\section{Discussion}

In our two experiments, we found that the effects of water on plant performance were

337 dependent on the presence of rhizobia and the genotype of the plant, suggesting that

338 understanding invasion success by Medicago polymorpha will require understanding abiotic,

339 biotic, and evolutionary factors. Water availability affected $M$. polymorpha performance in our greenhouse and botanical garden experiments, suggesting that the ability of this species to invade a particular habitat may depend on the spatial and temporal availability of water.

342 Adding rhizobia to the soil tended to increase plant size, indicating that the presence of

343 mutualists in the soil microbial community may increase the chances of invasion by this

344 legume. However, we found strong indirect effects of water and rhizobia on plant size, meaning that the total effects of water and rhizobia cannot be predicted in isolation of one another. Further, the direct and indirect effects of water and rhizobia on plant size varied widely depending on whether plant genotypes were collected from the native or invasive range of this species; plant genotype altered the direction and magnitude of direct and indirect ecological effects. In this species, predicting invasion into a natural community context will require understanding multiple direct and indirect effects in the local environment, as well as their effects on the specific genetic composition of the invading population.

We found that the amount of water provided to plants in both experiments affected

354 plant performance (total biomass), as well as growth allocation to above- and belowground 
biomass. In the greenhouse experiment, the effects of watering level were generally non-

356 linear (Fig. 1), suggesting that certain genotypes of M. polymorpha may perform best at

357 intermediate water levels. Previous work found that piñon pine (Pinus edulis) genotypes

358 originating in dry habitats performed better in drier soils (Mitton \& Duran, 2004). Similarly,

359 the genetic differences we observed could be the result of different evolutionary histories. We

360 minimized the effects of recent ecological environments using a common garden generation,

361 suggesting that the observed differences are not the result of phenotypic plasticity or maternal

362 effects, but rather inherited genetic differences. It is possible that the effects of water on our

363 different M. polymorpha genotypes may depend on long-term historic soil moisture in the

364 environments in which these genotypes evolved. Unfortunately, we do not have sufficiently

365 precise information about the original collection sites to obtain historic records to test this

366 hypothesis.

Previous studies suggest that plants grown under water stress will allocate more

energy toward belowground growth to increase root biomass and acquire more water resources (Matsui \& Singh, 2003; Goh et al., 2013; Saeed et al., 2016). Although we did not observe a consistent response to watering across genotypes in the greenhouse experiment, we

371 found that plants in the botanical garden experiment had the opposite response than

372 expected - plants grown in the low water treatment had relatively less root biomass. It is

373 possible that this is the result of an annual life history in plants native to a Mediterranean

374 climate, in which plants must grow as large as possible during a short, wet winter before soils

375 dry in the summer. Drier soils that signal the approach of summer may trigger a reproduction

376 response, rather than a long-term investment in water capture in longer-lived plants.

377 Regardless of the mechanism, this result suggests that allocation to above- or belowground

378 growth is somewhat plastic in this species, although the variation among genotypes suggests

379 that it is also partially genetically determined. 

conditions. Although rhizobia may directly enhance plant growth by providing nitrogen, such increased nutrients may only be valuable if no other resources are limiting. The exact mechanism of how rhizobia affect responses to watering treatment are unclear, but previous work demonstrates that bacteria may often affect plant stress responses. For example, the plant traits that rhizobia alter in response to nitrogen limitation, such as changes to lateral root density, root length, and shoot:root ratio (Goh et al., 2013; Kunert et al., 2016), may also alter plant responses to watering by increasing root surface area and the depth to which roots can grow to access water (Goh et al., 2013). Bacteria have also been observed to contribute to the resistance of Arabidopsis thaliana and Zea mays to abiotic stress by altering plant stress signal transduction (Chen et al., 2017). This can cause plasticity in the production of secondary metabolites, such as reactive oxygen species, which plants use as signals of environmental stress (Bailey-Serres \& Mittler, 2006), thereby indirectly increasing resistance to stress (Pandey et al., 2012; Goh et al., 2013). In addition, compounds secreted by some rhizobia increase the expression of plant genes whose products reduce sodium toxicity by sequestering $\mathrm{Na}+$ into vacuoles (Chen et al., 2017). Other non-rhizobia bacteria species (e.g. Pseudomonas aeruginosa) can increase salt tolerance and increase performance under low water conditions (Pandey et al., 2012). mutualistic to parasitic (Friesen et al., 2011; Jones et al., 2015) and the exact nature of the interaction likely depends on the evolutionary history of the plant, as well as the specific environmental context in which the interaction takes place. Although previous studies have 403 shown that the local availability of nitrogen affects the nature of the plant-rhizobia interaction 404 (Kiers et al., 2007; Oono et al., 2009; Weese et al., 2015), our results suggest that the 
405

406

407

408

409

410

411

412

413

414

415

416

417

418

419

420

421

422

423

424

425

426

427

428

429

availability of water may be important as well. The evolutionary history of the rhizobia may be important as well (Heath \& Tiffin, 2007). Although we only enhanced the soil with rhizobia collected locally from a single plant, we do not know the genetic diversity of the rhizobia in this treatment. Although $M$. polymorpha associates almost exclusively with Ensifer medicae (Porter et al., 2011), some plants can contain many strains of this rhizobia species (Djedidi et al., 2011). The genetic diversity of bacteria collected from a single plant, is certainly a very conservative subset of that found around the globe (Bromfield et al., 2010).

\section{Selection for traits during invasion}

We compared genotypes from the native and invasive range because we assumed that invasive genotypes would represent $M$. polymorpha traits that either facilitate invasion to new habitats around the globe, or are more adaptive in the invasive range relative to traits in the native range. However, because this species has invaded such a wide variety of locations around the globe, the traits that facilitate invasion may vary widely. Despite this expected variation among invasive genotypes, we still found some general trends in trait differences between genotypes collected from the invasive and native range. In both experiments, genotypes from the invasive range had, on average, lower shoot:root ratios. Size is often used as a proxy for competitive ability in invasive species (Blossey \& Notzold, 1995; Joshi et al., 2014), and if so, this suggests that belowground competitive ability for resources like water or nutrients increases $M$. polymorpha invasion success. This result is consistent with a previous study that showed greater investment in belowground biomass by invasive $M$. polymorpha genotypes (Getman-Pickering et al., 2018). However, that same study showed that size does not necessarily increase competitive ability against three co-occurring species in invaded California (USA) fields. It is possible that biomass allocation in this species may be in response to other factors besides competition, such as water, searching for rhizobia mutualists, or acquiring nitrogen in the absence of mutualist partners. 
431 Although the average effect of rhizobia on plant size was positive, different genotypes

432 experienced various magnitudes of positive and negative effects, depending on the watering

433 treatment. Native genotypes tended to benefit from rhizobia under high water conditions, but

434 invasive genotypes tended to benefit from rhizobia under low water conditions. The

435 mechanism underlying this difference is not yet clear, but the pattern suggests that invasive

436 and native genotypes interact with their environments in different ways. Given sufficient

437 water, invasive genotypes can grow large, even in the absence of partnerships with rhizobia,

438 and generally receive less overall benefit from rhizobia (terHorst et al., 2018). The ability to

439 invade without mutualists may give certain genotypes an advantage over others in novel

440 habitats. Perhaps invasive genotypes increased investment in belowground biomass allows

441 them to obtain sufficient nitrogen in the absence of nitrogen-fixing partners.

442 Relative importance of direct and indirect effects

443 Across studies of M. polymorpha that measured the effects of different ecological

444 interactions on various aspect of plant performance and fitness, we found that direct effects of

445 mutualism, nutrient level, and competition had the biggest effect on plants. The strong effects

446 of competition are perhaps not surprising, as many studies have demonstrated the importance

447 of competition with native plants on invasive plant species success (Boyden et al., 2005;

448 Jones \& Gomulkiewicz, 2012; Bever et al., 2012). Many studies focus on the role of natural

449 enemies in preventing invasion into novel habitats (Levine et al., 2004; Mitchell et al., 2006;

450 Duan et al., 2015) and how escaping natural enemies may allow increased investment in

451 competitive ability (Blossey \& Notzold, 1995). Similarly, many studies examine how

452 increased anthropogenic disturbances favor exotic species over native species that may not be

453 adapted to such disturbance regimes (Hobbs \& Huenneke, 1992; Seabloom et al., 2003;

454 Thomson \& Leishman, 2005; Price et al., 2011). However, the effects of drought or water 
availability on invasion success have been considered somewhat less and may stand out as important in this particular species that is historically adapted to a Mediterranean climate, where precipitation and water availability are highly seasonal. We were surprised to see that mutualisms ranked so highly in importance, but the generality of this result should be interpreted cautiously. Because we focused our short review only on this selfing legume species, all of the mutualist studies focused on soil microbes, and not on pollinators that may be especially important for other potential plant invaders. Nevertheless, the availability of mutualists, or lack thereof, has been historically understudied in invasive species and the increased attention such interactions have received in the past decade seems warranted.

Although we did not conduct a formal statistical analysis, in comparing abiotic and biotic direct effects on invasive and native genotypes of $M$. polymorpha, some general patterns emerged. Although mutualists have the strongest effects on this species overall, effects are much stronger on genotypes collected from the native range. Those genotypes collected in the invasive range seem to be relatively less affected by mutualists, suggesting that perhaps the strong effects of mutualists on this species do not play an equally large role in invasion success. In contrast, invasive genotypes are most affected by nutrient levels, drought, and herbivory. If invaders rely less on rhizobia for nitrogen, this may explain the increased importance of soil nitrogen for their success.

In the botanical garden, we found indirect effect sizes due to interactions between mutualists and drought rivaled those of the direct effects of drought, at least for invasive range genotypes. Even in the absence of strong direct effects, abiotic and biotic factors can have important influences on invasion success because of their involvement in indirect effects. For example, terHorst and Lau (2015) found no significant direct effects of herbivores and competitors on M. polymorpha performance, but strong indirect effects because herbivores reduced fruit production only in the presence of competitors. 
480 Given the data in our experiment, we would conclude that it is essential to incorporate

481 indirect ecological interactions in order to predict invasion success in natural diverse

482 communities. However, in our review of other studies, indirect ecological effects were almost

483 trivial relative to the strong direct effects observed. These few studies of indirect interactions

484 are not a random sample, but rather come entirely from two lab groups, including ours, and

485 were conducted only in greenhouses or field sites in California. Estimates of direct

486 interactions from our lab group were among the lowest in our review of other studies,

487 suggesting that perhaps our manipulations are less extreme than in other studies. The

488 relatively few estimates of indirect effects and limited scope suggest that further studies are

489 needed to determine the importance of indirect effects on invasion success more broadly.

490 Further, individual indirect effects may be weaker, on average, but the number of potential

491 indirect interactions can greatly outnumber direct interactions in diverse communities, as

492 simple and more complex indirect effects increase exponentially with increasing direct

493 interactions. In other systems, indirect effects have been found to increase (Suwa \& Louda,

494 2012) or decrease (Adams et al., 2003) invasion success in a community context. This

suggests that the total effect of any ecological interaction would be under- or overestimated

unless measured in the broader community context in which the interaction naturally occurs.

497 In both our system and in others, there are many potential indirect effects on invasion success

498 that have yet to be quantified.

Overall, these findings suggest that the relative magnitudes of direct and indirect

500 effects are context dependent. Though general trends emerge, including the importance of mutualism, nutrient level, and competition, the order and magnitude of these effects are

502 dependent upon the genetic composition of the invading $M$. polymorpha population. Our

503 review of previous studies suggests that indirect are unimportant relative to direct effects in

504 predicting invasion success of this species. However, the relatively large role that indirect 
effects play for some genotypes, particularly those that have already successful invaded other

506 habitats, suggests that more work is needed to determine the role that indirect plays in

507 invasion into complex natural habitats.

508

509 Acknowledgements

510 We thank Leah Bandak, Emma Collosi, Alejandro Flores, Aleena Hussain, and Katie Wong

511 for their help with maintaining and harvesting the experiments. Polly Schiffman and Peter

512 Edmunds provided valuable input on previous versions of the manuscript.

513

514 Funding: This work was funded by grants from the National Science Foundation to Ct (DEB-

5151754449 and OCE-1559105) and funding from Graduate Studies at CSUN to CH and NC and

516 the California Pre-doctoral Program, and the Southern California, Sherman Oaks, and Toluca

517 Lake Garden Clubs to NC.

518 Conflict of Interest: The authors declare that they have no conflict of interest.

519 Availability of data and materials: The datasets for this study will be uploaded to Dryad prior 520 to publication.

521

\section{Works cited}

523 Adams, M. J., Pearl, C. A., \& Bury, R. B. (2003). Indirect facilitation of an anuran invasion 524 by non-native fishes. Ecology Letters, 6(4), 343-351.

525 Algandaby, M. M., \& El-Darier, S. M. (2018). Management of the noxious weed; Medicago

526 polymorpha L. via allelopathy of some medicinal plants from Taif region, Saudi Arabia.

527 Saudi Journal of Biological Sciences, 25(7), 1339-1347.

528 Aslan, C. E. (2019). Implications of non-native species for mutualistic network resistance and $529 \quad$ resilience. PLoS ONE, 14(6), e0217498. 
Badri, M., Toumi, G., Mahfoudh, S., Hessini, K., Abdelguerfi-Laouar, M., Abdelguerfi, A., Aouani, M. E., Abdelly, C., \& Djébali, N. (2016). Diversity of response to drought in a collection of lines of Medicago truncatula, M. ciliaris, and M. polymorpha. Crop Science, 56(6), 3125-3132.

Bailey-Serres, J., \& Mittler, R. (2006). The roles of reactive oxygen species in plant cells. Plant Physiology, 141(2), 311.

Ballard, R. A., Charman, N., McInnes, A., \& Davidson, J. A. (2004). Size, symbiotic effectiveness and genetic diversity of field pea rhizobia (Rhizobium leguminosarum bv. viciae) populations in South Australian soils. Soil Biology and Biochemistry, 36(8), $1347-1355$.

Bayliss, S. L. J., terHorst, C. P., \& Lau, J. A. (2017). Testing genotypic variation of an invasive plant species in response to soil disturbance and herbivory. Oecologia, 183(4), $1135-1141$.

Berg, G., Grube, M., Schloter, M., \& Smalla, K. (2014). The plant microbiome and its importance for plant and human health. Frontiers in Microbiology, 5(SEP), 1.

Bever, J. D. (2015). Preferential allocation, physio-evolutionary feedbacks, and the stability and environmental patterns of mutualism between plants and their root symbionts. New Phytologist, 205(4), 1503-1514.

Bever, J. D., Platt, T. G., \& Morton, E. R. (2012). Microbial population and community dynamics on plant roots and their feedbacks on plant communities. Annual Review of Microbiology, 66(1), 265-283.

Bever, J. D., Westover, K. M., \& Antonovics, J. (1997). Incorporating the Soil Community into Plant Population Dynamics: The Utility of the Feedback Approach. In The Journal of Ecology (Vol. 85, Issue 5).

Blossey, B., \& Notzold, R. (1995). Evolution of Increased Competitive Ability in Invasive 
556 Boyden, S., Binkley, D., \& Senock, R. (2005). Competition and facilitation between

557 Eucalyptus and nitrogen-fixing Falcataria in relation to soil fertility. Ecology, 86(4),

$558 \quad 992-1001$.

559 Bromfield, E. S. P., Tambong, J. T., Cloutier, S., Prévost, D., Laguerre, G., van Berkum, P., 560 Tran Thi, T. V., Assabgui, R., \& Barran, L. R. (2010). Ensifer, Phyllobacterium and 561 Rhizobium species occupy nodules of Medicago sativa (alfalfa) and Melilotus alba 562 (sweet clover) grown at a Canadian site without a history of cultivation. Microbiology, $156(2), 505-520$.

Bullitta, S., Floris, R., Hayward, M. D., Loi, A., Porqueddu, C., \& Veronesi, F. (1994). Morphological and biochemical variation in Sardinian populations of Medicago polymorpha L. suitable for rainfed mediterranean conditions (pp. 223-232). Springer, Dordrecht.

Cavieres, L. A. (2021). Facilitation and the invasibility of plant communities. Journal of Ecology, 109(5), 2019-2028.

Chen, L., Xiang, S., Chen, Y., Li, D., \& Yu, D. (2017). Arabidopsis WRKY45 Interacts with the DELLA Protein RGL1 to Positively Regulate Age-Triggered Leaf Senescence. Molecular Plant, 10(9), 1174-1189.

573 Cipollini, D., \& Cipollini, K. (2016). A review of garlic mustard (Alliaria petiolata, Brassicaceae) as an allelopathic plant. In Journal of the Torrey Botanical Society (Vol. 143, Issue 4, pp. 339-348). Torrey Botanical Society. K., \& Halassy, M. (2016). Tree plantations are hot-spots of plant invasion in a landscape with heterogeneous land-use. Agriculture, Ecosystems and Environment, 226, 88-98. 
Dickie, I. A., Bufford, J. L., Cobb, R. C., Desprez-Loustau, M. L., Grelet, G., Hulme, P. E., Klironomos, J., Makiola, A., Nuñez, M. A., Pringle, A., Thrall, P. H., Tourtellot, S. G., Waller, L., \& Williams, N. M. (2017). The emerging science of linked plant-fungal invasions. New Phytologist, 215(4), 1314-1332.

Dill, L. M., Heithaus, M. R., \& Walters, C. J. (2003). Behaviorally mediated indirect interactions in marine communities and their conservation implications. Ecology, 84(5), 1151-1157.

Djedidi, S., Yokoyama, T., Tomooka, N., Ohkama-Ohtsu, N., Risal, C. P., Abdelly, C., \& Sekimoto, H. (2011). Phenotypic and genetic characterization of rhizobia associated with alfalfa in the Hokkaido and Ishigaki regions of Japan. Systematic and Applied Microbiology, 34(6), 453-461.

Duan, J. J., Bauer, L. S., Abell, K. J., Ulyshen, M. D., \& Van Driesche, R. G. (2015). Population dynamics of an invasive forest insect and associated natural enemies in the aftermath of invasion: Implications for biological control. Journal of Applied Ecology, $52(5), 1246-1254$.

Duchicela, J., Vogelsang, K. M., Schultz, P. A., Kaonongbua, W., Middleton, E. L., \& Bever, J. D. (2012). Non-native plants and soil microbes: Potential contributors to the consistent reduction in soil aggregate stability caused by the disturbance of North American grasslands. New Phytologist, 196(1), 212-222.

Edwards, G. R., Bourdôt, G. W., \& Crawley, M. J. (2000). Influence of herbivory, competition and soil fertility on the abundance of Cirsium arvense in acid grassland.

603 Everard, K., Seabloom, E. W., Harpole, W. S., \& De Mazancourt, C. (2010). Plant water use 604 affects competition for nitrogen: Why drought favors invasive species in California. 
606 Fang, K., Wang, Y. Z., \& Zhang, H. B. (2019). Differential effects of plant growth-promoting bacteria on invasive and native plants. South African Journal of Botany, 124, 94-101.

Friesen, M. L., Porter, S. S., Stark, S. C., Von Wettberg, E. J., Sachs, J. L., \& MartinezRomero, E. (2011). Microbially mediated plant functional traits. Annual Review of Ecology, Evolution, and Systematics, 42, 23-46.

611 Getman-Pickering, Z. L., terHorst, C. P., Magnoli, S. M., \& Lau, J. A. (2018). Evolution of increased Medicaco polymorpha size during invasion does not result in increased competitive ability. Oecologia, 188(1), 203-212.

Gianoli, E., Quezada, I. M., \& Suárez, L. H. (2009). Leaf damage decreases fitness and constrains phenotypic plasticity to drought of a perennial herb. Acta Oecologica, 35(5), $752-757$.

617

Goh, C. H., Veliz Vallejos, D. F., Nicotra, A. B., \& Mathesius, U. (2013). The Impact of Beneficial Plant-Associated Microbes on Plant Phenotypic Plasticity. Journal of Chemical Ecology, 39(7), 826-839.

González-Moreno, P., Pino, J., Carreras, D., Basnou, C., Fernández-Rebollar, I., \& Vilà, M. (2013). Quantifying the landscape influence on plant invasions in Mediterranean coastal habitats. Landscape Ecology, 28(5), 891-903.

Halliday, J., \& Somasegaran, P. (1983). Nodulation, nitrogen fixation, and Rhizobium strain affinities in the genus Leucaena. Leucaena Research in the Asian-Pacific Region. Proceedings of a Workshop Held in Singapore, 23-26 November 1982., 27-32. Traxler, M. F. (2020). Cooperation, competition, and specialized metabolism in a simplified root nodule microbiome. MBio, 11(4), 1-20.

Heath, K. D., \& Tiffin, P. (2007). Context dependence in the coevolution of plant and 

274(1620), 1905-1912.

Hillebrand, H., Frost, P., \& Liess, A. (2008). Ecological stoichiometry of indirect grazer effects on periphyton nutrient content. Oecologia, 155(3), 619-630.

Hobbs, R. J., \& Huenneke, L. F. (1992). Disturbance, Diversity, and Invasion: Implications for Conservation. Conservation Biology, 6(3), 324-337.

Huenneke, L. F., Hamburg, S. P., Koide, R., Mooney, H. A., \& Vitousek, P. M. (1990). Effects of soil resources on plant invasion and community structure in Californian serpentine grassland. Ecology, 71(2), 478-491.

Jack, C. N., \& Friesen, M. L. (2019). Rapid evolution of Medicago polymorpha during invasion shifts interactions with the soybean looper. Ecology and Evolution, 9(18), $10522-10533$.

642 Jayne, B., \& Quigley, M. (2014). Influence of arbuscular mycorrhiza on growth and reproductive response of plants under water deficit: a meta-analysis. Mycorrhiza, 24(2), $109-119$.

Jones, E. I., Afkhami, M. E., Akçay, E., Bronstein, J. L., Bshary, R., Frederickson, M. E., Heath, K. D., Hoeksema, J. D., Ness, J. H., Pankey, M. S., Porter, S. S., Sachs, J. L., Scharnagl, K., \& Friesen, M. L. (2015). Cheaters must prosper: Reconciling theoretical and empirical perspectives on cheating in mutualism. Ecology Letters, 18(11), 12701284.

Jones, E. I., \& Gomulkiewicz, R. (2012). Biotic interactions, rapid evolution, and the

652 Joshi, S., Gruntman, M., Bilton, M., Seifan, M., \& Tielbörger, K. (2014). A comprehensive 653 test of evolutionarily increased competitive ability in a highly invasive plant species. 654 Annals of Botany, 114(8), 1761-1768. 
655 Kiers, E. T., Hutton, M. G., \& Denison, R. F. (2007). Human selection and the relaxation of 656 legume defences against ineffective rhizobia. Proceedings of the Royal Society B: 657 Biological Sciences, 274(1629), 3119-3126.

658 Kinnaird, M. F., \& O’Brien, T. G. (1998). Ecological Effects of Wildfire on Lowland 659 Rainforest in Sumatra. Conservation Biology, 12(5), 954-956.

660 Knutson, K. C., Pyke, D. A., Wirth, T. A., Arkle, R. S., Pilliod, D. S., Brooks, M. L.,

661 Chambers, J. C., \& Grace, J. B. (2014). Long-term effects of seeding after wildfire on 662 vegetation in Great Basin shrubland ecosystems. Journal of Applied Ecology, 51(5), $663 \quad 1414-1424$.

664 Kuhman, T. R., Pearson, S. M., \& Turner, M. G. (2013). Why does land-use history facilitate 665 non-native plant invasion? A field experiment with Celastrus orbiculatus in the southern 666 Appalachians. Biological Invasions, 15(3), 613-626.

Kulmatiski, A., Beard, K. H., \& Stark, J. M. (2006). Soil history as a primary control on plant invasion in abandoned agricultural fields. Journal of Applied Ecology, 43(5), 868-876.

Kunert, K. J., Vorster, B. J., Fenta, B. A., Kibido, T., Dionisio, G., \& Foyer, C. H. (2016). Drought stress responses in soybean roots and nodules. Frontiers in Plant Science.

Lau, J. A., \& Strauss, S. Y. (2005). Insect herbivores drive important indirect effects of exotic plants on native communities. Ecology, 86(11), 2990-2997.

673 Lentile, L. B., Morgan, P., Hudak, A. T., Bobbitt, M. J., Lewis, S. A., Smith, A. M. S., \& Robichaud, P. R. (2007). Post-Fire Burn Severity and Vegetation Response Following Eight Large Wildfires Across the Western United States. Fire Ecology, 3(1), 91-108. exotic plant invasions. Ecology Letters, 7(10), 975-989. natural enemies and biotic resistance hypotheses. Oikos, 95(3), 361-373. 
680

681

682

683

684

685

686

687

688

689

690

691

692

693

694

695

696

697

698

699

700

701

702

703

704

Marschner, P., Yang, C. H., Lieberei, R., \& Crowley, D. E. (2001). Soil and plant specific effects on bacterial community composition in the rhizosphere. Soil Biology and Biochemistry, 33(11), 1437-1445.

Matsui, T., \& Singh, B. B. (2003). Root characteristics in cowpea related to drought tolerance at the seedling stage. Experimental Agriculture, 39(1), 29-38.

McGlone, C. M., Sieg, C. H., \& Kolb, T. E. (2011). Invasion resistance and persistence: Established plants win, even with disturbance and high propagule pressure. Biological Invasions, 13(2), 291-304.

Mitchell, C. E., Agrawal, A. A., Bever, J. D., Gilbert, G. S., Hufbauer, R. A., Klironomos, J. N., Maron, J. L., Morris, W. F., Parker, I. M., Power, A. G., Seabloom, E. W., Torchin, M. E., \& Vázquez, D. P. (2006). Biotic interactions and plant invasions. Ecology Letters, $9(6), 726-740$.

Mitton, J. B., \& Duran, K. L. (2004). Genetic variation in piñon pine, Pinus edulis, associated with summer precipitation. Molecular Ecology, 13(5), 1259-1264.

Moser, W. K., Barnard, E. L., Billings, R. F., Crocker, S. J., Dix, M. E., Gray, A. N., Ice, G. G., Kim, M. S., Reid, R., Rodman, S. U., \& McWilliams, W. H. (2009). Impacts of nonnative invasive species on US forests and recommendations for policy and management. Journal of Forestry, 107(6), 320-327.

Oono, R., Denison, R. F., \& Kiers, E. T. (2009). Controlling the reproductive fate of rhizobia: How universal are legume sanctions? New Phytologist, 183(4), 967-979.

Pages, J. P., \& Michalet, R. (2003). A test of the indirect facilitation model in a temperate hardwood forest of the northern French Alps. Journal of Ecology, 91(6), 932-940.

Paini, D. R., Sheppard, A. W., Cook, D. C., De Barro, P. J., Worner, S. P., \& Thomas, M. B. (2016). Global threat to agriculture from invasive species. Proceedings of the National Academy of Sciences of the United States of America, 113(27), 7575-7579. 
Pandey, P. K., Yadav, S. K., Singh, A., Sarma, B. K., Mishra, A., \& Singh, H. B. (2012).

706

707

708

709

710

711

712

713

714

715

716

717

718

719

720

721

722

723

724

725

726

727

728

729 Cross-Species Alleviation of Biotic and Abiotic Stresses by the Endophyte Pseudomonas aeruginosa PW09. Journal of Phytopathology, 160(10), 532-539.

Porter, S. S., \& Simms, E. L. (2014). Selection for cheating across disparate environments in the legume-rhizobium mutualism. Ecology Letters, 17(9), 1121-1129.

Porter, S. S., Stanton, M. L., \& Rice, K. J. (2011). Mutualism and adaptive divergence: Coinvasion of a heterogeneous grassland by an exotic legume-rhizobium symbiosis. PLoS ONE, 6(12).

Price, J. N., Berney, P. J., Ryder, D., Whalley, R. D. B., \& Gross, C. L. (2011). Disturbance governs dominance of an invasive forb in a temporary wetland. Oecologia, 167(3), 759769.

Rand, T. A. (2003). Herbivore-mediated apparent competition between two salt marsh forbs. Ecology, 84(6), 1517-1526.

Revillini, D., Gehring, C. A., \& Johnson, N. C. (2016). The role of locally adapted mycorrhizas and rhizobacteria in plant-soil feedback systems. Functional Ecology, 30(7), 1086-1098.

Richardson, D. M., Allsopp, N., D’antonio, C. M., Milton, S. J., \& Rejmánek, M. (2000). Plant invasions — the role of mutualisms. Biological Reviews, 75(1), 65-93.

Rosenblatt, A. E. (2018). Shifts in plant nutrient content in combined warming and drought scenarios may alter reproductive fitness across trophic levels. Oikos, 127(12), 18531862.

Saeed, M., Ilyas, N., Akram, A., Raja, N., Mazhar, R., Bibi, F., Seerat, W., Kanwal, S., \& Batool, N. (2016). Effect of drought stress on Brassica crops and its mitigation by inoculation of PGPR. International Journal of Biosciences (IJB), 9(6), 282-291.

Seabloom, E. W., Harpole, W. S., Reichman, O. J., \& Tilman, D. (2003). Invasion, 
competitive dominance, and resource use by exotic and native California grassland species. Proceedings of the National Academy of Sciences of the United States of America, 100(23), 13384-13389.

Shabbir, A., Dhileepan, K., Zalucki, M. P., Khan, N., \& Adkins, S. W. (2020). Reducing the fitness of an invasive weed, Parthenium hysterophorus: Complementing biological control with plant competition. Journal of Environmental Management, 254, 109790.

Somasegaran, P., \& Hoben, H. J. (1985). Methods in Legume-Rhizobium technology.

Strauss, S. Y. (1991). Indirect effects in community ecology: Their definition, study and importance. Trends in Ecology and Evolution, 6(7), 206-210.

Suwa, T., \& Louda, S. M. (2012). Combined effects of plant competition and insect herbivory hinder invasiveness of an introduced thistle. Oecologia, 169(2), 467-476.

terHorst, C. P., Wirth, C., \& Lau, J. A. (2018). Genetic variation in mutualistic and Drought Stress. Frontiers in Ecology and Evolution, 7, 262.

terHorst, C. P., \& Zee, P. C. (2016). Eco-evolutionary dynamics in plant-soil feedbacks. Functional Ecology, 30(7), 1062-1072.

Thalmann, M., \& Santelia, D. (2017). Starch as a determinant of plant fitness under abiotic stress. New Phytologist, 214(3), 943-951.

Thomson, V. P., \& Leishman, M. R. (2005). Post-fire vegetation dynamics in nutrientenriched and non-enriched sclerophyll woodland. Austral Ecology, 30(3), 250-260. in a perennial herb. Plant Biology, 15(2), 335-343. addition causes the evolution of less-cooperative mutualists. Evolution, 69(3), 631-642. 
755 Wootton, J. T. (1994). The nature and consequences of indirect effects in ecological

756 communities. Annual Review of Ecology and Systematics, 25, 443-466.

757 Yousfi, N., Saïdi, I., Slama, I., \& Abdelly, C. (2015). Phenology, leaf gas exchange, growth 758 and seed yield in Medicago polymorpha L. populations affected by water deficit and 759 subsequent recovery. Flora: Morphology, Distribution, Functional Ecology of Plants, $760 \quad 214,50-60$.

761 Zefferman, E., Stevens, J. T., Charles, G. K., Dunbar-Irwin, M., Emam, T., Fick, S., Morales, 762 L. V., Wolf, K. M., Young, D. J. N., \& Young, T. P. (2015). Plant communities in harsh 763 sites are less invaded: A summary of observations and proposed explanations. In $A o B$ 764 PLANTS (Vol. 7, Issue 1). Oxford University Press.

765

Ziegel, E. R., Scheiner, S., \& Gurevitch, J. (1995). Design and Analysis of Ecological

766 Experiments. Technometrics, 37(1), 128.

767

768

769

770

771

772

773

774

775

776

777

778

779 


\section{Figure captions}

781 Figure 1. Effects of increasing watering levels on means (+/- SEM) of different genotypes of

782 M. polymorpha (A) total biomass and (B) above:belowground biomass in the greenhouse

783 experiment.

784

785 Figure 2. Effects of watering levels on (A) total biomass and (B) above:belowground biomass

786 (means +/- SEM) of M. polymorpha genotypes collected from the invasive or native range in

787 the botanical garden experiment.

788

789 Figure 3. The log response ratio of each genotype (color coded by their collection range) to

790 decreased watering in rank order in the background rhizobia treatment (A). The same order of

791 genotypes along the $\mathrm{x}$-axis is presented in the enhanced rhizobia treatment (B).

792

793 Figure 4. Effect size of different direct effects and pooled indirect effects (+/- SEM) on $M$.

794 polymorpha distinguished by native or invasive range.

795

796

797

798

799

800

801

802

803

804 
A

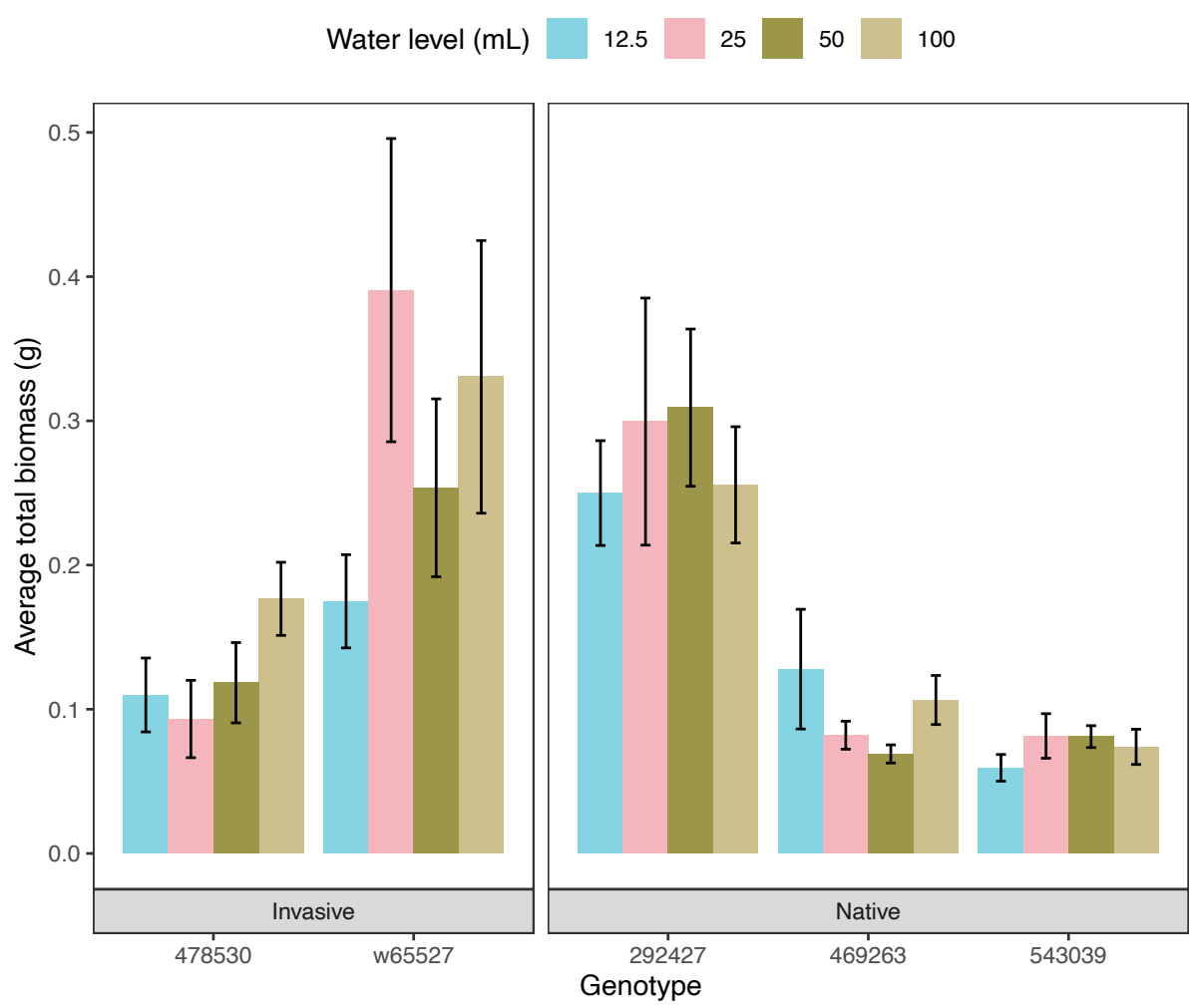

B

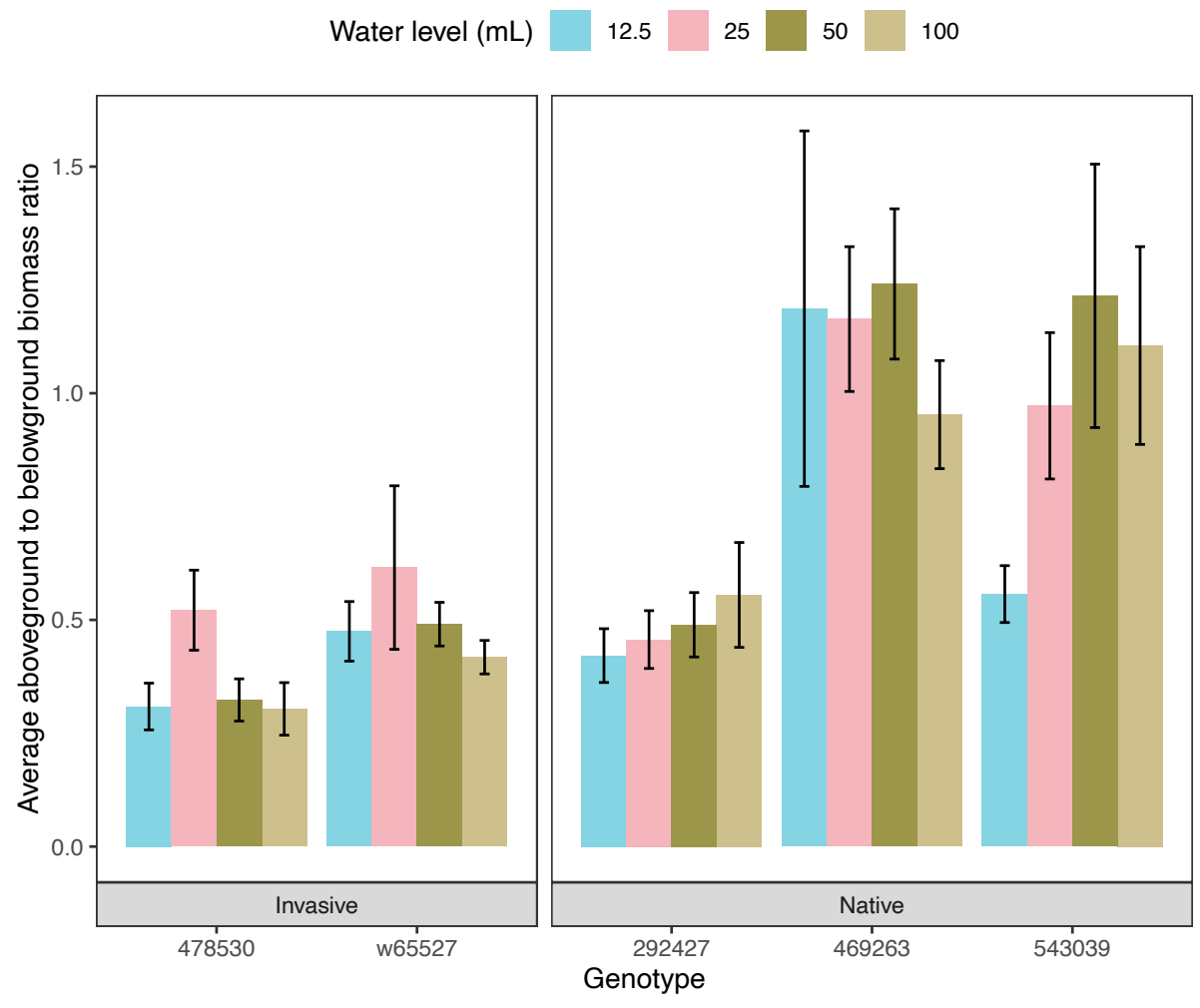

806 Figure 1. 

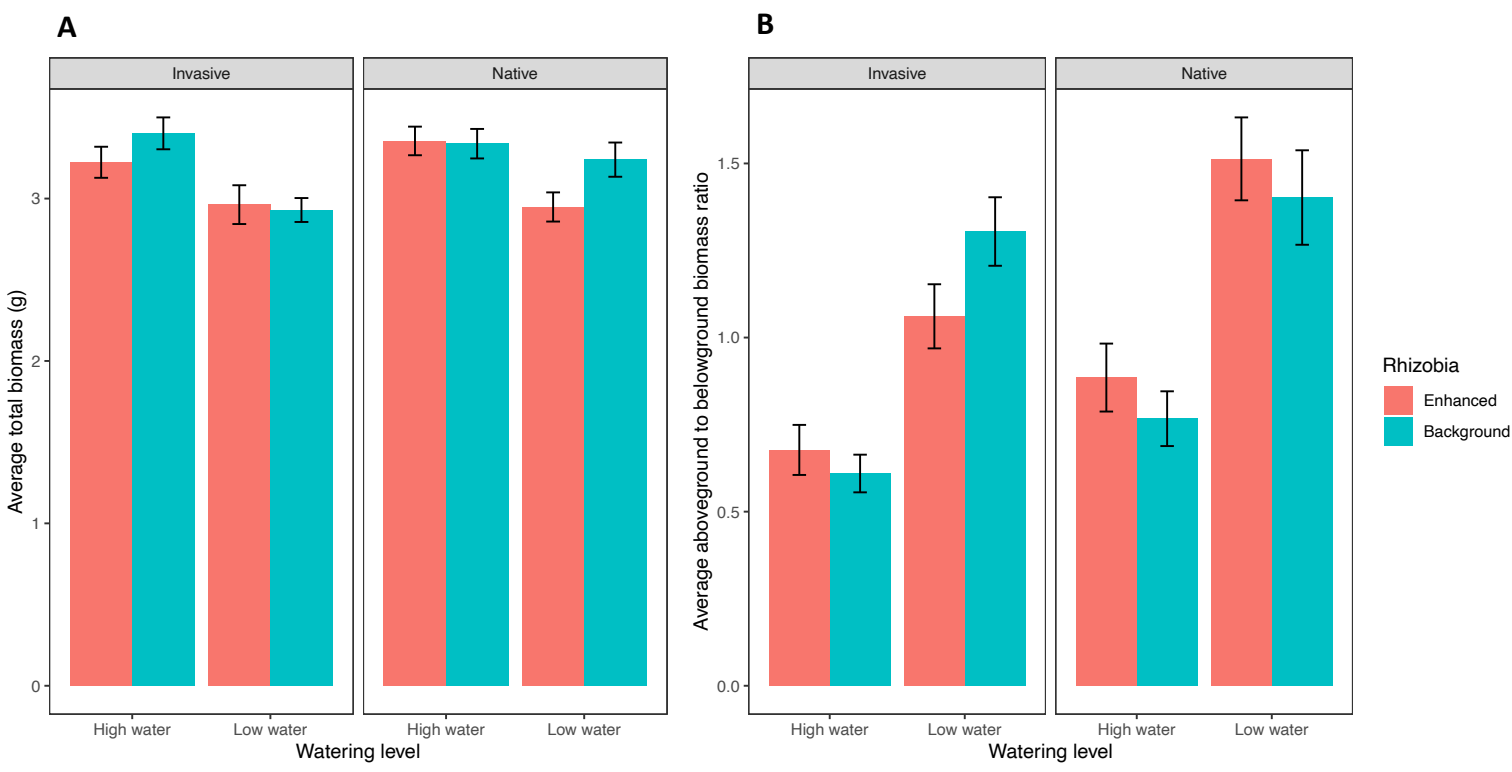

807

808 Figure 2.

809

810

811

812

813

814

815

816

817

818

819

820

821

822

823 
品 品 $\quad$ \&

$\stackrel{w}{\sim}$

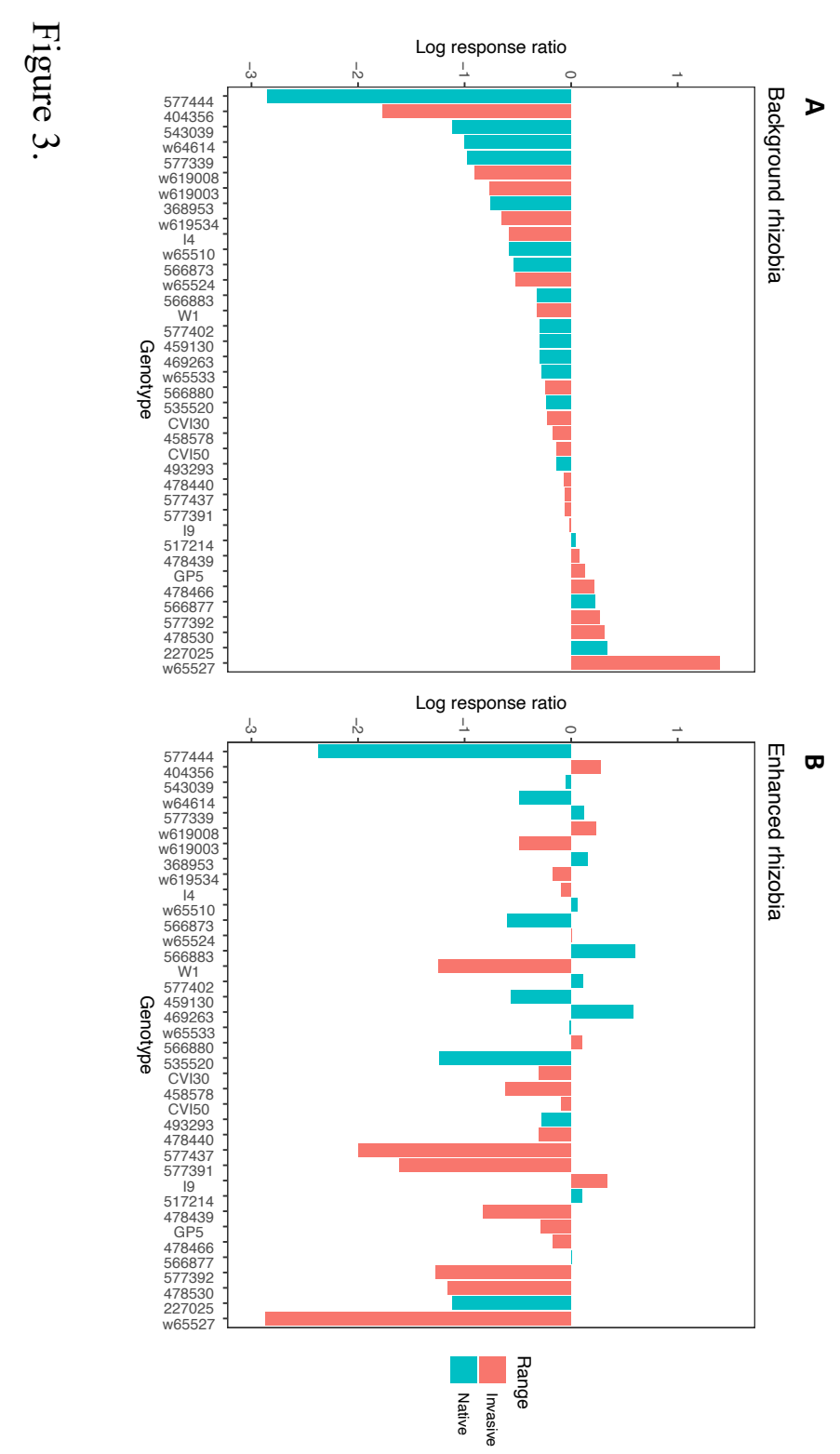




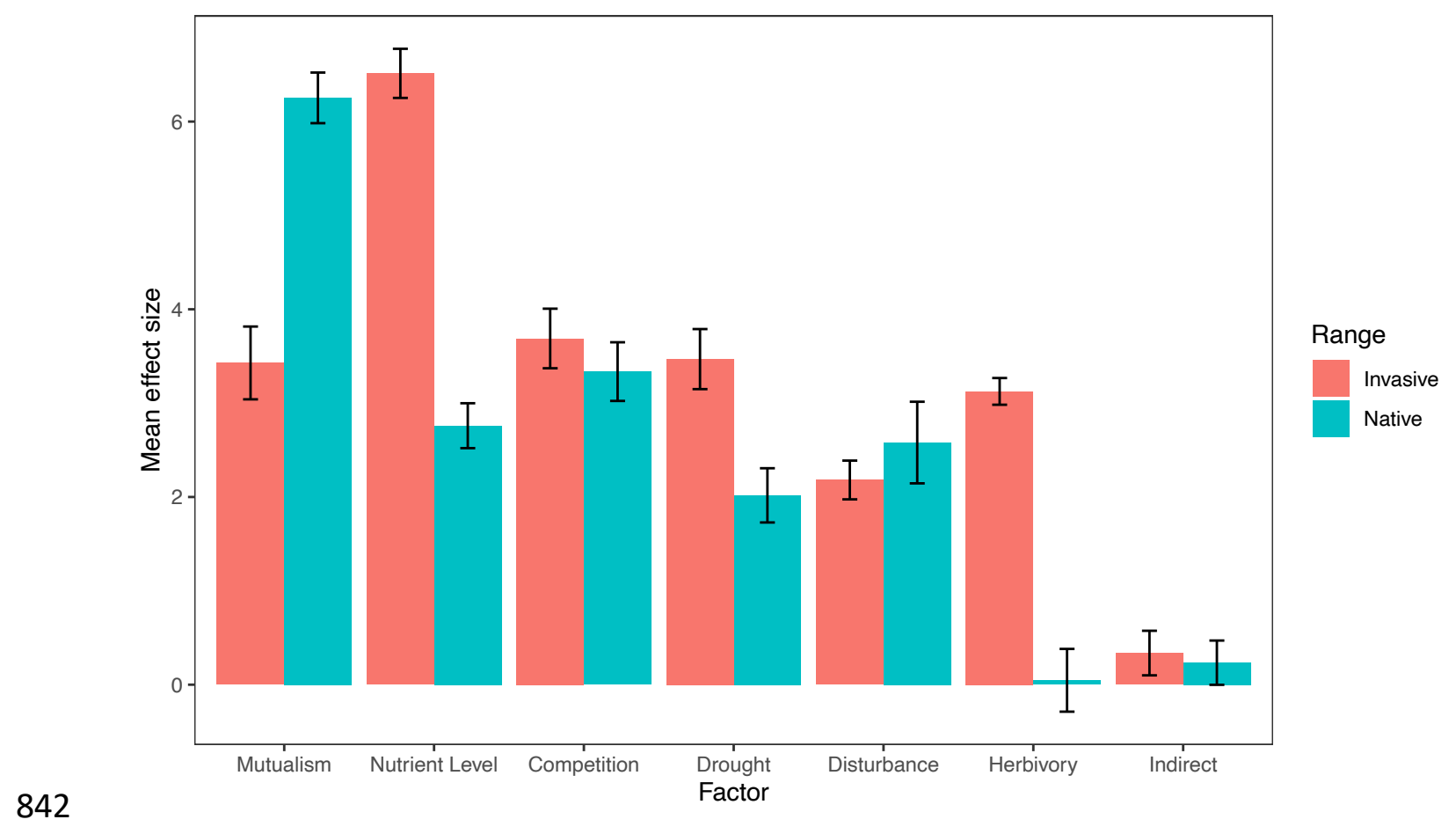

843 Figure 4. 


\section{Supplementary Files}

This is a list of supplementary files associated with this preprint. Click to download.

- Supplementalmaterial.docx 